\title{
Assessing resilience to floods from a holistic perspective in French Polynesia
}

\author{
Heinzlef $C^{1}$, Morschel $J^{1}$, Serre $D^{1}$ \\ ${ }^{1}$ UMR 241 EIO, Université de la Polynésie Française
}

\begin{abstract}
The increase in flood events intensity and recurrence has considerably weakened urban areas and populations. The material and human damages led to social, economic, political, political and environmental impacts that can weaken the urban scale but also the national or even international scale. Faced with this, scientists and managers integrate the resilience concept into risk strategies. Resilience is defined as the ability of a system to absorb disturbances, maintain its functions and restart activities after it. However, resilience is still a concept difficult to operationalize. The objective of this research is therefore to propose an approach to address this lack of operationality. While some researches tried to operationalize the concept of resilience it is essentially a technical and organizational resilience, without taking into consideration the systemic dimension of the territory. This research therefore aims to operationalize the concept of resilience at the communal level through the creation of a decision-making tool, addressing resilience in the most holistic way possible, around three indicators in order to analyze urban, social and technical resilience characteristics. The idea behind this approach is that urban resilience embodies the abilities and capacities of a city and its population to develop before, during and after a disruptive event in order to limit its negative impacts. This scientific positioning therefore makes possible to analyze urban resilience as a continuum, highlighting proactive capacities that the urban system must develop in order to (re)act in the face of flooding. The originality of the methodology is justified by a collaborative approach, characterized by a socio-economic partnership with local actors. This approach is a part of a longer-term reflection to define the first steps in the construction of an Urban Resilience Observatory focusing on the design and dissemination of theoretical and practical knowledge around urban risk and resilience issues in order to reach the consensus needed for action and decision-making with a particular focus in French Polynesia.
\end{abstract}

\section{Introduction - A Polynesian context}

In a context of climate change, island territories are increasingly vulnerable to an increase in the recurrence and intensity of risks (David, 2011). On French territory, French Polynesia alone represents $40 \%$ of the EEZ (Fig.1) and is therefore a source of significant wealth and resources. However, space occupation, economy and resources are highly vulnerable to the increase in disasters on these territories and to the related uncertainties. This increasing vulnerability raises the question of the spatial and temporal equity (Bertrand and Richard, 2011) of island territories and raises questions about risk mitigation and management measures. The multiplication of risks and their recurrence calls into question the sustainability of the primary and economic resources of these territories, particularly with ocean acidification, sea level rise and the associated risks of submersion, erosion but also the increase in more specific events such as floods or storms. The January 2017 floods that hit Tahiti are a case in point. In 6 days, $498 \mathrm{~mm}$ of water fell on Faaa International Airport (Fig.2), $197 \mathrm{~mm}$ of which fell on the 1st day. This is almost twice as much as the monthly normal (1981 / 2010) of $254 \mathrm{~mm}$.

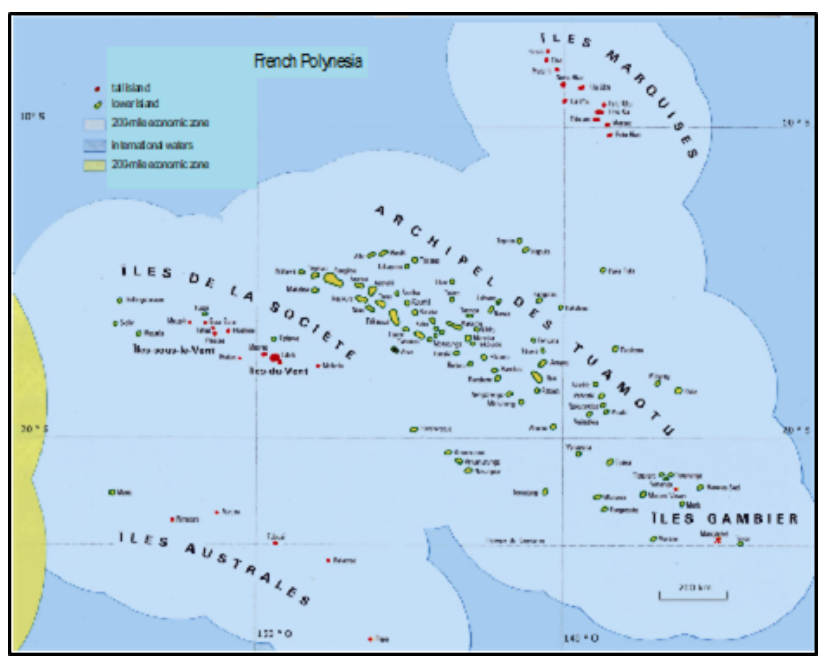

Figure 1: French Polynesian EEZ

\footnotetext{
a Corresponding author: damien.serre@upf.pf

DOI 10.3311/FLOODRisk2020.13.7
} 
The airport has been closed as the runways are under water. Floods and landslides caused heavy damage over most of the island and six thousand homes were deprived of electricity.

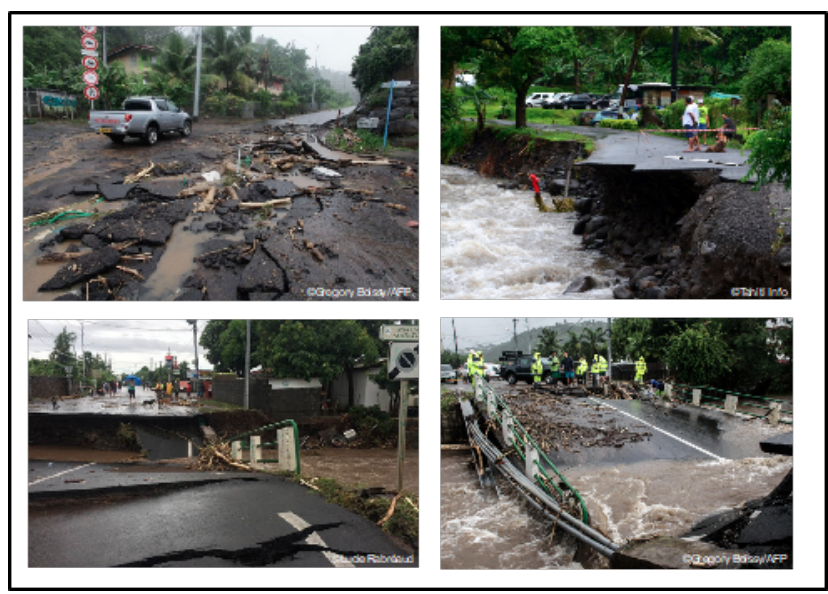

Figure 1: Impacts of floods in 2017 - Tahiti

This succession of risks affects not only environmental elements but also the daily life of populations, their places and their quality of life in the more or less long term (Berthe and Ferrari, 2015). Faced with the dual observation of the increase in risk and vulnerability of island territories and the lack of ownership and operationalization of the concept of resilience, this approach seeks to develop a methodology to promote the integration of resilience into risk management strategies in the Pacific islands. The stakes and uncertainties linked to climate disruption are leading risk management strategies to evolve, in order to prepare Pacific territories and populations to adapt to increasing risks (Leal Filho, 2017). Resilience is today an essential concept for coping with and preparing for the increasing risks. However, this concept is also confronted with operational limitations, which limit its integration into the management strategies of local actors. The proposed methodology aims to respond to the theoretical and practical limitations of the concept by working together with local planners and stakeholders to integrate resilience into risk management strategies.

In the first part, we will analyze the concept of resilience and its difficult integration into risk management strategies. We will then present an operationalization methodology tested on an urban territory, followed by a research project aimed at adapting this methodology to the island territories of French Polynesia.

\section{The Concept of Resilience as a New Entry Point in Risk Management}

Over the past two decades, resilience has become a key concept in risk management. Belonging to the disciplines of physics (Ionescu, 2012), psychology (Cyrulnik, 2004) and ecology (Holling, 1973), resilience became part of risk management in the 2000s. Resilience is then defined as "the capacity of a system, community or society exposed to risks to resist, adapt to and recover quickly and effectively from negative effects (...). A community's resilience to potential hazards is defined by the resources it has and puts in place to adapt and organize itself before, during and after shocks" (UNISDR-United Nations International Strategy for Disaster Reduction, 2009). The altered system must be able to evolve, adapt and restore or maintain a functioning equilibrium (Barroca et al., 2012). Resilience has a multitude of meanings and refers as much to a capacity to resist as to a capacity to absorb and recover (Serre, 2016), a capacity to learn (Vale and Campanella, 2005; Zevenbergen, 2016), or a capacity to adapt. In contrast to the negative connotation of vulnerability, resilience embodies a positive and innovative dimension. Whatever the definition behind this term, it always refers to a return to an acceptable equilibrium, whether it is prior to the shock or a new functioning. It is therefore a notion that refers to a technical, urban, social, architectural, economic and political innovation and calls for a rethinking of our risk management systems. This injunction to innovation is perfectly adapted to the urban, economic, political, social and ecological complexity of the contemporary world. As a result, the concept of resilience is integrated into territorial issues and associated risks. However, its multidisciplinary use makes it a polysemic and abstract concept, turning it into a buzzword (Djament-Tran et al., 2011). This multitude of disciplinary affiliations limits its understanding and integration into clear and relevant risk management strategies, which calls into question its operationalization (Fig.3).

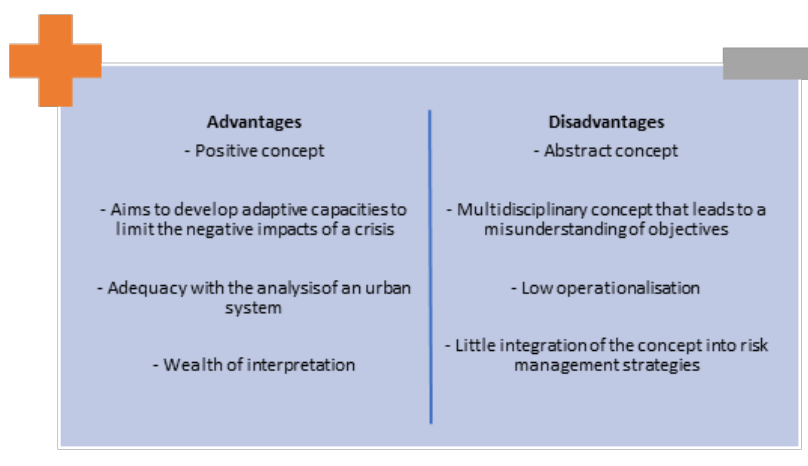

Figure 3: Advantages and disadvantages of resilience concept

\section{The challenges of operationalizing resilience}

Some methodologies and tools currently exist to integrate this concept into risk management strategies. These tools seek to design indicators for measuring and assessing resilience in order to lead to a spatial mapping of the concept.

Over the last ten years or so, the use of indicators has spread in the field of risk, and more specifically in the measurement of the vulnerability and resilience of territories and populations to risks (Cutter et al., 2008). If the use of indicators has increasingly developed in risk management, it is notably due to their capacity to measure 
and/or operationalize a variable to describe an extraordinary phenomenon (Øien, 2001). Indicators are valued for their ability to integrate large amounts of information in an easily understandable form, making them valuable tools for analysis, communication and action (Freudenberg, 2003). For this reason, indicators are regularly used to characterize, analyze and operationalize concepts such as vulnerability and resilience.

The first tool for operationalizing the concept of resilience is the BRIC (Baseline Resilience Indicators for Communities; (Cutter et al., 2008)). After developing the SoVI, Cutter's team turned to the concept of resilience in order to build a database of resilience indicators, the BRIC (Cutter et al., 2008). This has made it possible to construct 6 indicators to measure resilience: social, economic, community, institutional, infrastructural and environmental. Each indicator is divided into subvariables such as education, age, language proficiency, employment rate, immigration rate, access to food, disaster training, social stability, access to health or access to energy. Each variable has a positive or negative effect on community resilience. Once the data had been acquired from national statistical services, data processing and "cleaning" work was necessary. The processing method chosen was Min-Max. Min-Max normalization assigns a value of 0 to the minimum value and 1 to the maximum value. While this method greatly facilitates comparison across a large number of variables, the disadvantage is that the final score is not an absolute measure of community resilience for a single location, but rather a relative value against which multiple sites can be compared. For this reason, the proposed work is done at the US scale (Fig.4) and not at a finer scale or for a single year, as it is not a diachronic work.

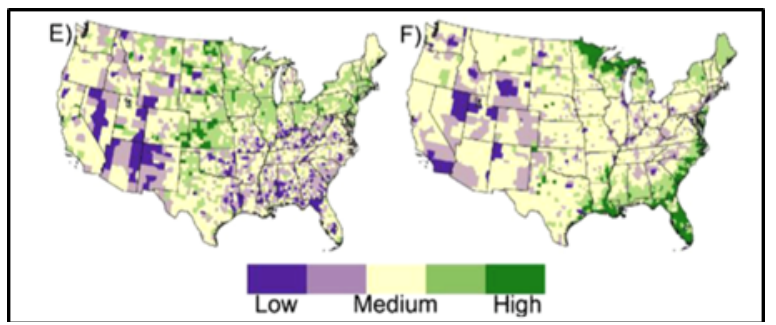

Figure 2: U.S. - wide resilience

The BRIC methodology is relevant because it proposes a range of indicators to provide a mapping of assumed resilience across the United States. The article by Cutter et al. (2008) provides indicators that are comprehensive enough to analyze the many elements that make up the territorial system: the social, economic, community, institutional, infrastructural and environmental. The main bias of this approach remains the scale of analysis, which is not fine enough to lead to decision-making and a change in planning and risk management trends.

The second tool used is the DS3 Model (Serre, 2018). This is a tool for modelling technical-functional resilience. This approach has identified three capabilities for assessing the resilience of urban networks to flood risk. Resilience is defined here as the capacity of a system to absorb a disturbance and subsequently recover its functions. Three capacities are assumed to determine the degree of resilience of these networks:

- Resilience capacity: this consists in determining the material damage following a risk. The model assumes that the more a network is damaged, the more likely it is to malfunction and the slower and more complex it is to return to service;

- Absorption capacity: it illustrates the weaknesses and strengths of the network, allowing alternatives to be built to the network following a component failure;

- Recovery capacity: this represents the time required to bring the network and its components back into service.

This approach has helped to promote understanding of the interdependence of a city's technical and critical networks by developing key resilience capacities for the networks. Tested at the local level, this methodology has made it possible to diagnose a neighbourhood and its critical infrastructures. The progress of this work has led to the identification of resilience criteria for critical infrastructures and urban networks. However, this approach does not allow for a global approach to resilience and the territory at risk. It is therefore necessary to broaden the approach to the concept and its analysis in order to promote understanding and adoption of the concept.

\section{A French holistic methodology for resilience operationalization}

If resilience is a concept that promotes innovation, learning, by highlighting capacities for rebounding, recovery, flexibility and adaptation, the concept is still complex to operationalize for local actors. Some research has attempted to respond to operational biases, but very few succeed in analysing urban resilience on a local scale and via an exhaustive approach, i.e. by analysing the entire complexity of the territory, through all the components that make up the urban space. This research therefore seeks to address resilience globally and on a local scale in order to promote decision support.

\subsection{Scientific position}

This study retains the idea that territorial resilience embodies the aptitudes and capacities of a territory and its population to implement actions before, during and after a disruptive event in order to limit its negative impacts. This scientific positioning therefore makes it possible to analyse territorial resilience as a continuum, highlighting proactive capacities that the urban system must develop in order to (re)act in the face of the disaster, thereby developing learning and anticipation skills. Resilience is therefore no longer a skill that can only be observed after the crisis, but rather a concept that defines a learning process (Brand and Jax, 2007; Davidson-Hunt and Berkes, 2002; Gunderson and Holling, 2002) via a culture of risk (Laganier, 2015)nover a long period of time, during which the shock is only a triggering and revealing element of the system's intrinsic capacities. From this point of view, 
resilience and vulnerability are no longer in opposition but participate in defining the inherent characteristics of the system. The shock then makes it possible to highlight these resiliencies and/or vulnerabilities.

\subsection{A holistic methodology}

Our research shows that the approach to resilience must focus on the multiple social and territorial dimensions and interactions. Our goal is to understand and highlight the characteristics that could influence urban resilience. Keeping in mind that resilience is considered as a capacity of a society or a territory to plan, adapt, absorb, recover, learn, evolve, we have tried to select some inherent social, technical territorial features (Fig. 5) that would allow the development of a resilient territory.

Three indicators have been defined to apprehend territorial resilience in the most holistic way possible, an indicator of urban, technical and social resilience:

- Urban resilience: We consider that the indicator of territorial resilience includes all urban dynamics physical such as buildings (building age, density, functionality) or critical infrastructure - or virtual such as economic dynamics, assessed by the creation or disappearance of new commercial properties. For example, for critical infrastructures, we measure their influence on the scope of action. Critical infrastructures can be defined as infrastructures that concentrate all the functions necessary for the proper functioning of a territory and its population (Pescaroli and Kelman, 2017). They are defined as "critical" because in a crisis situation, their potential destruction could weaken the entire organization of a territory. We have established variables to understand the degree of territorial resilience, taking into account the area of influence of critical infrastructures (fire, police, defense forces), access to health, social housing density, tourism dynamics and economic (creation and maintenance of old businesses).

- Technical resilience: By technical variables, we mean all interconnected physical components such as urban networks. Transport, gas, electricity and water networks (their age, resistance, absorption and recovery capacity, according to Serre, 2016) are included in this indicator. Indeed, recent research highlights the impact (negative and/or positive) of urban networks during and after a crisis. They are essential to the proper functioning of a city, connecting more and more people and territories and thus offering a variety of resources and opportunities, but they can also create situations of interdependence (Serre and Heinzlef, 2018). A single failure can create cascading effects affecting the whole city, due to the reticular urban system (Serre and Heinzlef, 2018). For this indicator, we have developed the methodology of the DS3 Model (Serre, 2018), which defines three characteristics for analysing the resilience of urban networks: resistance, absorption and recovery capacities.

- Social resilience: Social resilience can be defined as the ability of a population to adapt and recover from disturbances (Hutter and Lorenz, 2018). In this study, we understand social resilience as social community resilience and not as individual resilience (Hutter and Lorenz, 2018). Many factors can enable a social entity to act, react and proactively develop activities or interactions, such as age (Cutter et al., 2010), political investment (Voss, 2008), socio-economic status (Flanagan et al., 2011), knowledge and perception of risk, diversity, etc. (Hutter and Lorenz, 2018). The main idea is to pay more attention to the capacities and resources of a population in order to proactively adapt the components to potential disruption (Hutter and Lorenz, 2018; Serre and Heinzlef, 2018). Let us not forget that the population revitalizes the territory after a crisis and that social resilience can make the difference between vulnerability and resilience (Hutter and Lorenz, 2018).

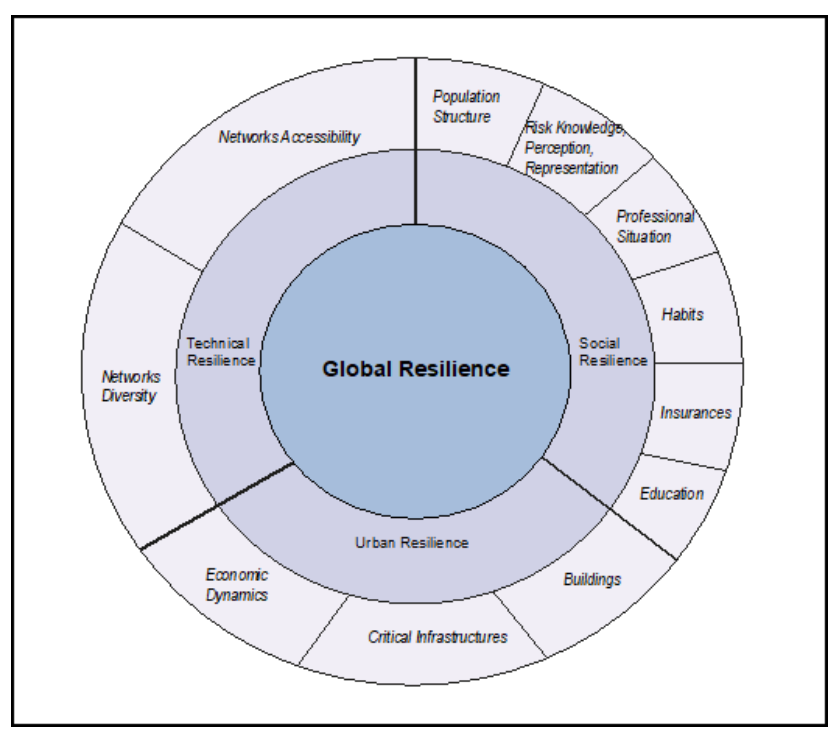

Figure 5: Three resilience indicators (Heinzlef et al., 2019)

This model for defining and measuring resilience has made it possible to clarify the theoretical concept and to address resilience over a long period of time in order to respond to territorial limits, fractures and fragilities in the face of flood risk. The choice to use $90 \%$ of the data in open data (INSEE) favours the adaptation of this methodology to other territories, at least on all French cities, which use INSEE data. In addition, the fact that this tool is co-constructed makes it possible to directly integrate the needs and approaches of municipal managers. Unlike some case studies on the measurement of resilience (Fox-Lent et al., 2015; Serre et al., 2016), this study does not apply its methodology a posteriori to a territory subject to a given risk, but begins by considering the integration of the specificities of the territory and especially its governance, a necessary step in a collaborative and participatory decision-making tool. In this way, comparative work could lead to an exchange of feedback between the different territories, which could lead to a French resilience index. Moreover, the choice of open source tools or tools used by French local authorities makes the tool more accessible to urban services. 
Consequently, this methodology provides a holistic approach to analysing the resilience potential of an urban system. While the concept of resilience remains imprecise and subjective, this work makes it possible to perceive the characteristics of resilience that a territory must develop, for instance an attractive territory for young and dynamic populations (Fig. 6). The tool is therefore more in line with urban planners' risk practices and strategies.

This methodology was designed, validated and tested on the urban territory of Avignon (Serre and Heinzlef, 2018; Heinzlef et al., 2019), a territory at the confluence of the Rhone and Durance rivers and subject to the challenges of urban flooding.

Such a model, complemented by long-term research methods and tools, such as an observatory, should provide useful results for the implementation of resilience strategies in the Pacific islands.

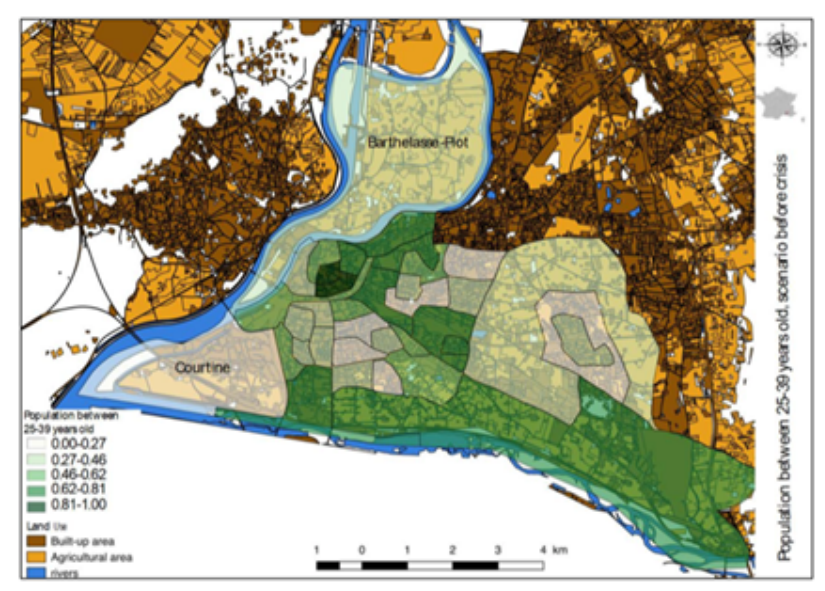

Figure 6: Social resilience in Avignon scale - Population between 25 and 39 years old (Heinzlef, 2019)

\section{A Polynesian spatial decision support system to improve territorial resilience}

In view of the growing vulnerability of island territories to risks and climate change, the conceptual and operational interest of the concept of resilience and its difficult spatial, local and operational integration, the interest of working on a Polynesian spatial decisionsupport tool takes on its full meaning.

Indeed, the French Overseas Islands accumulate strong hydro-meteorological hazards with methods, tools and risk management strategies that are often inadequate. This statement comes from a 2014 French government report explaining that the French overseas islands are highrisk areas, without effective risk management systems and with a lack of resources dedicated to this issue. Floods (river, rain, tsunamis and submersions) are among the most critical problems for most of the islands. Improving resilience to flood risk in such an area is therefore a key challenge. Faced with this observation, a research project led by the IRD and the CNRS has been set up in order to respond to the challenges of operationalizing resilience in French Polynesia. The aim of this Pacific Island Long
Term reSilience (ILOTS) project is to initiate reflection on a Resilience Observatory in order to work on the limits and biases of the concept and its operationalization (Serre, 2019).

Adapting the holistic methodology tested on the metropolitan territory, we suggest to:

- Model the level of resilience to flooding and cascading effects of two French Polynesian islands (Tahiti and Moorea) by focusing on the issues of importance to Polynesians. To do so, we aim to test and improve, if necessary, the resilience models developed in other contexts such as the model built and tested in Avignon;

- Design long-term means through a risk and resilience observatory to accumulate and share knowledge, then develop functions allowing decision-makers to choose the most interesting resilient options to prepare and adapt these islands to extreme events.

At the end of the project, we expect to have a first idea of the level of flood resilience of these islands and a preliminary list of the functions of such an observatory. Such a prototype Resilience Observatory developed for Moorea and Tahiti could help decision-makers to strategically plan land use in a long-term perspective.

\section{Conclusion}

This paper presents a methodology to overcome the biases of the operationalization of resilience. This methodology, built around three measurement indicators (urban, technical and social resilience), has made it possible to measure resilience at the local urban scale. The choice of data, their accessibility, and the collaborative approach have made it possible to promote the integration of the concept into risk management practices.

The challenge today is to adapt this metropolitan methodology to vulnerable territories faced with increasing risks in a context of climate disruption.

Faced with increasingly recurrent and intense risks, economic and natural resources are likely to be sustainably impacted, weakening the Polynesian island territories. Faced with this current and future vulnerability, the concept of resilience offers a diversity of responses and strategies to prepare territories and populations for the increase in risks. However, this concept is still very abstract and little integrated into current risk management strategies. Therefore, the scientific project ILOTS has defined as an objective the design of a Resilience Observatory in order to respond to these operational and theoretical issues and limitations of the concept, in order to meet the challenges of French Polynesia.

\section{Acknowledgements}

This project has received financial support from the CNRS through the MITI interdisciplinary programs and from the IRD.

\section{References}


1. Barroca, B., Serre, D., Youssef, D., 2012. Le concept de résilience à l'épreuve du génie urbain. VertigO Rev. Électronique En Sci. L'environnement 12.

2. Berthe, A., Ferrari, S., 2015. Justice écologique et adaptation au changement climatique : le cas des petits territoires insulaires. Rev. Philos. Économique 16, 103. https://doi.org/10.3917/rpec. 161.0103

3. Bertrand, F., Richard, E., 2011. Adaptation des territoires insulaires : éléments de réflexion à partir de deux îles françaises (Ré et La Réunion). VertigO. https://doi.org/10.4000/vertigo.10473

4. Brand, F.S., Jax, K., 2007. Focusing the Meaning(s) of Resilience: Resilience as a Descriptive Concept and a Boundary Object. Ecology and Society 12.

5. Cutter, S.L., Barnes, L., Berry, M., Burton, C., Evans, E., Tate, E., Webb, J., 2008. A place-based model for understanding community resilience to natural disasters. Glob. Environ. Change 18, 598-606. https://doi.org/10.1016/j.gloenvcha.2008.07.013

6. Cutter, S.L., Burton, C.G., Emrich, C.T., 2010. Disaster Resilience Indicators for Benchmarking Baseline Conditions. J. Homel. Secur. Emerg. Manag. 7. https://doi.org/10.2202/1547-7355.1732

7. Cyrulnik, B., 2004. La Résilience ou comment renaître de sa souffrance? Penser le monde de l'enfant. Fabert.

8. David, G., 2011. Existe-t-il une spécificité insulaire face au changement climatique? VertigO. https://doi.org/10.4000/vertigo. 10530

9. Davidson-Hunt, I.J., Berkes, F., 2002. Nature and society through the lens of resilience: toward a human-in-ecosystem perspective, in: Berkes, F., Colding, J., Folke, C. (Eds.), Navigating SocialEcological Systems. Cambridge University Press, Cambridge, pp. 53-82.

https://doi.org/10.1017/CBO9780511541957.006

10. Djament-Tran, G., Le Blanc, A., Lhomme, S., Rufat, S., Reghezza-Zitt, M., 2011. Ce que la résilience n'est pas, ce qu'on veut lui faire dire.

11. Flanagan, B.E., Gregory, E.W., Hallisey, E.J., Heitgerd, J.L., Lewis, B., 2011. A Social Vulnerability Index for Disaster Management. $J$. Homel. Secur. Emerg. Manag. 8.

https://doi.org/10.2202/1547-7355.1792

12. Fox-Lent, C., Bates, M.E., Linkov, I., 2015. A matrix approach to community resilience assessment: an illustrative case at Rockaway Peninsula. Environ. Syst. Decis. 35, 209-218. https://doi.org/10.1007/s10669-015-9555-4

13. Freudenberg, M., 2003. Composite Indicators of Country Performance (OECD Science, Technology and Industry Working Papers No. 2003/16). https://doi.org/10.1787/405566708255

14. Gunderson, L.H., Holling, C.S. (Eds.), 2002. Panarchy: understanding transformations in human and natural systems. Island Press, Washington, DC.

15. Heinzlef, C., 2019. Modélisation d'indicateurs de résilience urbaine face au risque d'inondation. Coconstruction d'un système spatial d'aide à la décision pour contribuer à l'opérationnalisation du concept de résilience. Avignon Université.
16. Heinzlef, C., Becue, V., Serre, D., 2019. Operationalizing urban resilience to floods in embanked territories - Application in Avignon, Provence Alpes Côte d'azur region. Saf. Sci. 118, 181-193. https://doi.org/10.1016/j.ssci.2019.05.003

17. Holling, C.S., 1973. Resilience and stability of ecological systems. Annu. Rev. Ecol. Syst. 4, 1-23.

18. Hutter, G., Lorenz, D.F., 2018. Social Resilience, in: Vulnerability and Resilience to Natural Hazards. Cambridge University Press, pp. 190-213.

19. Ionescu, S., 2012. Origine et évolution du concept de résilience, in: Résilience, Connaissances de Base. $\mathrm{p}$. 222.

20. Laganier, R., 2015. La résilience organisationnelle: se préparer et faire face à la crise, in: Résiliences: Sociétés et Territoires Face À L'incertitude, Aux Risques et Aux Catastrophes. ISTE éd., pp. 141-158.

21. Leal Filho, W., 2017. Climate Change Adaptation in Pacific Countries: Fostering Resilience and Improving the Quality of Life. Springer, Cham.

22. Øien, K., 2001. Risk indicators as a tool for risk control. Reliab. Eng. Syst. Saf. 74, 129-145. https://doi.org/10.1016/S0951-8320(01)00067-9

23. Pescaroli, G., Kelman, I., 2017. How Critical Infrastructure Orients International Relief in Cascading Disasters. J. Contingencies Crisis Manag. 25, 56-67. https://doi.org/10.1111/1468-5973.12118

24. Serre, D., 2019. Risques Naturels - AAP 2019 Projets ILOTS. IRD - CNRS, Polynésie Française.

25. Serre, D., 2018. DS3 Model Testing: Assessing Critical Infrastructure Network Flood Resilience at the Neighbourhood Scale, in: Fekete, A., Fiedrich, F. (Eds.), Urban Disaster Resilience and Security. Springer International Publishing, Cham, pp. 207220. https://doi.org/10.1007/978-3-319-68606-6_13

26. Serre, D., 2016. Advanced methodology for risk and vulnerability assessment of interdependency of critical infrastructure in respect to urban floods. E3S Web Conf. 7, 7002. https://doi.org/10.1051/e3sconf/20160707002

27. Serre, D., Barroca, B., Balsells, M., Becue, V., 2016. Contributing to urban resilience to floods with neighbourhood design: the case of Am Sandtorkai/Dalmannkai in Hamburg. J. Flood Risk Manag. https://doi.org/10.1111/jfr3.12253

28. Serre, D., Heinzlef, C., 2018. Assessing and mapping urban resilience to floods with respect to cascading effects through critical infrastructure networks. Int. J. Disaster Risk Reduct. https://doi.org/10.1016/j.ijdrr.2018.02.018

29. UNISDR-United Nations International Strategy for Disaster Reduction, 2009. Terminology on disaster risk reduction. Geneva.

30. Vale, L.J., Campanella, T.J., 2005. The Resilient City, how modern Cities Recover from Disaster. Broché.

31. Voss, M., 2008. The vulnerable can't speak. An integrative vulnerability approach to disaster and climate change research. Behemoth 1. https://doi.org/10.1524/behe.2008.0022

32. Zevenbergen, C., 2016. Flood Resilience, in: Resource Guide on Resilience, IRGC 2016. 